\title{
PROGRAM FOR THE RATIONAL CHOICE OF HIGHLY COST-EFFECTIVE ADAPTIVE TECHNOLOGY OF GRAIN CULTIVATION FOR VARIOUS CONDITIONS OF THE EUROPEAN PART OF THE RUSSIAN FEDERATION
}

\author{
Andrey Valerievich Gostev ${ }^{1 *}$, Alexey Ivanovich Pykhtin ${ }^{2}$, Semenova Liudmila ${ }^{2}$ \\ ${ }^{1}$ Federal Agricultural Kursk Research Center, Kursk, Russian Federation \\ ${ }^{2}$ Southwest State University, Kursk, Russian Federation
}

Currently, a promising area of agricultural development in Russia and in the world is the development of software for digitalization of agriculture. Based on the analysis of regional scientific researches on the use of the most effective combinations of resource-saving agricultural techniques in grain cultivation technologies, a software application has been developed; it allows users to automatically generate individualized adaptive agricultural techniques for cultivating 12 crops for 8 regions of the European part of the Russian Federation, based on the entered values of key indicators of agricultural landscape. The work consistently addresses the issues of the need for digitalization of agriculture, describes the results of ongoing research on this topic, outlines the directions for further research on such developments, and, based on authors' research presents the stage-by-stage process of developing and testing application software. As a result of the research, a finished product was created and tested i.e. a computer program that solves not only the problem of increasing the efficiency of grain cultivation, but also ensuring the environmental orientation of the technologies due to the efficient use of fertilizers, fuel and chemical plant protection products, choice of the optimal variety or hybrid of crops, and used farming equipment, based on import substitution and calculation of the chosen agrotechnology cost-effectiveness, which is extremely important and relevant at present. The proposed software package consists of a client-server application for personal computers, a Web application, a mobile application for smartphones based on the Android operating system, two databases (for personal computers and for the online version of the application).

Key words: software, decision support, database, digital agriculture

\section{INTRODUCTION}

In relation to the active development of information technology, the digitalization of production processes plays a decisive role in the competitiveness and distribution of leading positions among developed countries. That is why at present the issue of the development of the digital economy affects almost all areas of activity.

The Russian Federation is no exception in regard to this global trend. According to Russian Government Executive Order No 1632-r of 28 July 2017, the State Program "Digital Economy of the Russian Federation" was approved; it states that digital data is a key production factor in all areas of socio-economic activity, which increases the country's competitiveness, citizens' quality of life, provides economic growth and national sovereignty. However, according to the information published in this Program, in terms of the readiness to apply economic and innovative results in digital technologies, Russia is ranked 38th among the countries-leaders lagging far behind Scandinavian countries, Norway, Israel, Singapore, Netherlands, USA, Luxembourg and Germany.

Thus, with 120 million hectares of arable land and being the largest exporter of grain, Russia lags significantly behind and occupies only $15^{\text {th }}$ position in terms of digitaliza- tion of agriculture. In particular, according to the Ministry of Agriculture of the Russian Federation, only $10 \%$ of Russian agro-enterprises make decisions based on digital farming, while in the USA this figure is about $60 \%$ and in the EU countries it is even higher - $80 \%$ [1].

Therefore, the transition of our country to the digital economy is considered as a key driver of economic growth and improving the economic condition of the state. Thus, the use of digital technology in the agricultural sector allows increasing the profitability of agricultural production due to point optimization of costs and more effective distribution of funds. New conditions of digital economy allows reducing costs by $23 \%$ by means of implementing a new integrated approaches.

World practices and the experience of successful domestic agricultural producers demonstrate that even at the current stage, application of modern digital technology allows us to create optimal soil-agrotechnical and organizational-territorial conditions that ensure a significant increase in yield and labour productivity, a decrease in material costs for fuels and lubricants, electricity, plant protection products, labour and other types of expenses, preservation of soil fertility and environmental protection during the entire life cycle of agricultural products [2].

Modern researchers consider digital technologies as an 
integral part of the agricultural sector in the near future: rom decision support systems for crop planning to irrigation automation, digital modelling and yield forecasting [3].

The main considerations in support of the digitalization of agricultural production are the need to solve the following topical problems associated with Russia's lagging behind the advanced countries of the world [4-5]:

- Increase in the quantity and quality of the crop [4-5];

- Minimization of capital investments [4-5];

- Reduction of labour intensity and increase in agricultural productivity [4-5];

- Reduction of harmful effects on the environment [4-5];

- Reduction of the dependence on the human factor in agriculture and yield deviation [4-5].

It should also be noted that agriculture is a dynamic system, influenced by many factors, so, for the effective cultivation of crops during the growing season, it is necessary to make more than 40 different organizational and managerial decisions regarding the choice of varieties and hybrids, a type, a dose and a technique of fertilizer application, the appropriateness of the main tillage, the rate of seeding, measures to protect crops and harvesting. The amount of possible crop losses, both quantitatively and qualitatively, depends on the correctness of the decision made. Therefore, to reduce the likely loss of the crop, scientifically based decisions relying on the analysis of the existing conditions should be made. With regard to digitalization of agriculture, such decisions should be expressed in the maximum automation of the basic agrotechnological techniques.

The Strategy for Scientific and Technological Development of the Russian Federation [6], approved by the Decree of the President of the Russian Federation No 642 of 1 December 2016, in relation to the agricultural industry, highlights 2 key challenges:

1. Exhaustion of Russia's economic growth possibilities, based on extensive exploitation of raw materials, against the backdrop of the digital economy formation and the emergence of a limited group of countries-leaders with new manufacturing technologies [6];

2. The need to ensure food security and food independence of Russia, the competitiveness of domestic products on the world food markets, reduction of technological risks in the agricultural sector [6].

Based on these challenges, it is proposed to consider the following problems to be the priorities of scientific and technological development of the Russian Federation in the next 10-15 years:

1. The transition to advanced digital, intelligent manufacturing technologies [6];

2. The transition to a highly productive and environmentally friendly agro-farming, the development and implementation of the systems of rational application of chemical and biological crop protection products [6].
As part of solving these priority challenges, the trend in modern research and development has shifted to the area of information systematization and accumulation, analysis of heterogeneous data, creation of new mathematical models and adaptation of the existing ones and based on them automated or automatic decision-making. Current Russian studies (V. K. Kalichkin (Siberian Federal Research Center for Agrobiotechnology), V. V. Yakushev (AFI), E. V. Lutsenko (Kuban GAU), L. V. Tiranova (Novgorod Scientific Research Institute of Agriculture), V. M. Bure (St. Petersburg State University) as well as foreign ones (Deepak Keshwani (State University of North Carolina, USA), Dennis Commarano (Cambridge, England) etc.) are devoted to these issues [7-13]. Nevertheless, until 2019 at the Federal Institute of Industrial Property there has been no registered software based on the analysis of the available soil-climatic and material resources that allows forming an agrotechnology in an automated mode. A family of similar software products was developed by the Government of Western Australia - "MyCrop Wheat", "MyCrop Barley", etc. At the same time, actually these programs are reference books for some varieties of cereals including their description, possible pests, etc. There are no elements of decision support in these programs.

The purpose of this research is to develop a scientifically-based system of the choice of adaptive technology for the cultivation of grain crops in the European part of Russia for agricultural producers' decision support, which allows them to choose the necessary grain crop cultivation technology, including soil and climatic conditions of a particular territory, and thereby, contribute to increasing the profitability of grain production, to ensure environmental orientation through the efficient use of fertilizers, fuel and chemical plant protection products, the choice of crops varieties (hybrids), and used agricultural machinery [7].

According to the results of the All-Russian Agricultural Census, the leading crops for the European part of Russia are: wheat (27800 thousand ha), barley (8400 thousand ha), oats (3000 thousand ha), corn for grain (2900 thousand ha), rye (1300 thousand ha), buckwheat (1200 thousand ha), peas (1100 thousand ha), and millet (400 thousand ha) [14]. Taking into account the contrasting soil, climatic and landscape conditions of the area under study, the analysis and generalization of the results of long-term and short-term field experiments on the development and optimization of technologies or individual techniques of grain crops cultivation were carried out differentially for each enlarged region of the European part of Russia (from North and North-West to Volga regions).

To optimize the process of the rational choice of highly profitable adaptive technology, it was decided to gradually achieve the goal by developing and subsequently integrating helper applications in a single platform that provide evidence-based choice of the main agrotechnological techniques for cultivating main crops based on 
the analysis of existing conditions and their compliance with regulatory values of second level information arrays:

- For the choice of varieties and hybrids of grain crops;

- For the choice of systems for fertilizing, tillage, and plant protection;

- For the choice of techniques of sowing and harvesting, including agricultural machinery.

\section{RESULTS AND DISCUSSION}

Currently, the State Register of Selection Achievements Authorized for Use for Production Purposes allowed on the territory of the Russian Federation [15] includes more than 3,000 different varieties and hybrids of grain crops, the choice of which seems to be a rather difficult task even for expert agronomists. The decision to cultivate a particular variety or hybrid is subjective and is based mainly on the general recommendations of research institutions for the regions, successful marketing campaigns of seed companies, experience in using varieties or hybrids in the neighboring agricultural companies, or the conservative opinion of the heads of agricultural organizations. Thus, modern high-tech agricultural produc- tion is in the need of the development and application of techniques, algorithms and software for the choice of varieties and hybrids of agricultural crops, taking into account the agro-technological and soil-climatic features of the agricultural system.

The process of variety changing associated with changes in climatic,weather, environmental, economic and other conditions is a fairly common occurrence in agriculture and, therefore, there is a reliable probability of the need for the development of such application for agricultural producers. At the first stage of the declared studies, a "Program for the Scientifically-based Choice of Varieties and Hybrids of Grain Crops" [16] was developed in the form of a client-server system for personal computers implemented on the technological platform "1C: Enterprise 8.3", a Web application, a mobile application for smartphones based on the Android operating system "Grain Crops: Choice of Varieties and Hybrids", two databases (for personal computers and for the online version of the application) (Fig. 1-2). At the $21^{\text {st }}$ Russian Golden Autumn 2019 agricultural exhibition, this software package was awarded a silver medal and a diploma.

Admin Crops Variety Parameters Levels Crop parameters Croplevels Stability User Pykhtin A.I. -

\section{Crop levels}

\begin{tabular}{ll} 
Crop name & Parameter name \\
\hline Seed peas & Drought resistance \\
\hline Seed peas & Drought resistance \\
\hline Seed peas & Drought resistance \\
\hline Seed peas & Drought resistance
\end{tabular}

Level name
High standard
At the standard level
It doesn't matter
Low standard

Action

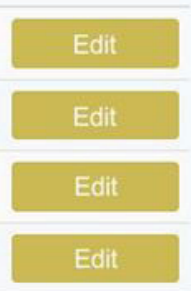

Figure 1: Web-interface of the computer program for the scientifically-based choice of grain crops varieties and hybrids

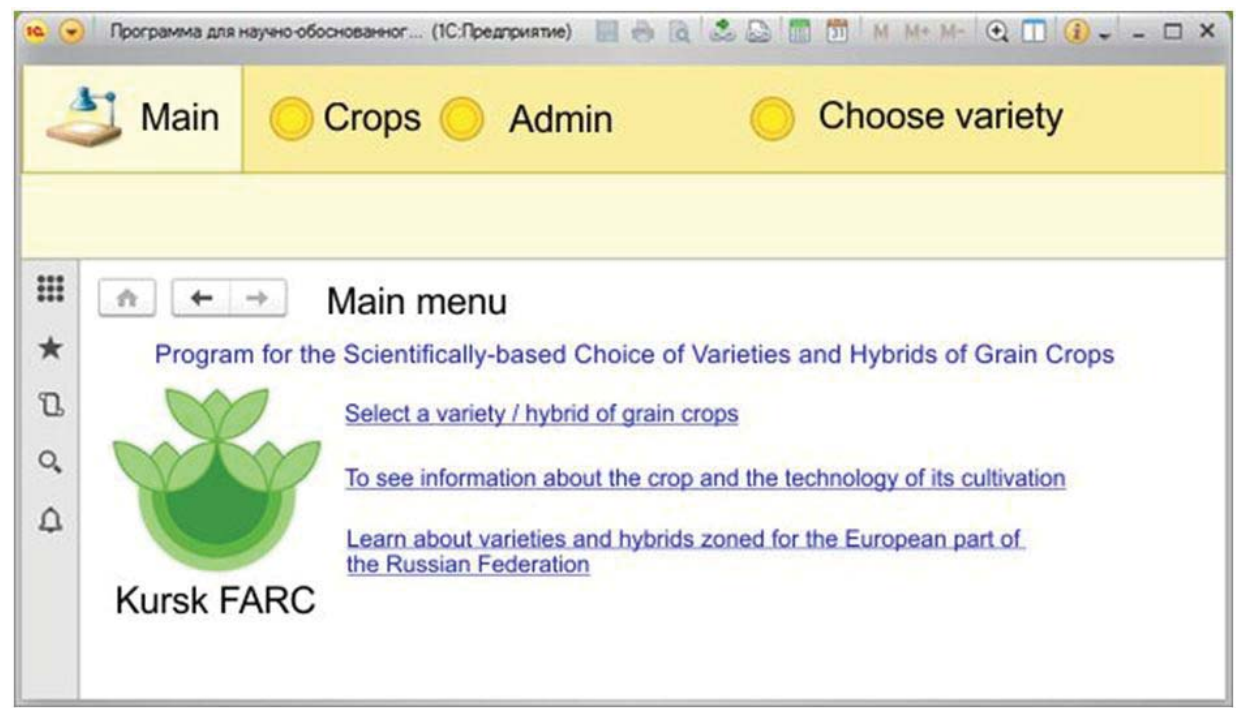

Figure 2: The user interface of the computer programfor the scientifically based choice of grain crops varieties and hybrids implemented on the "1C: Enterprise 8.3" technological platform 
The website is publicly available (http://alimlios.beget. tech), the mobile application is located in the Google Play Market directory. Access to the application is free. Access to the administrative part, implemented on the 1C: Enterprise 8.3 platform, is denied; it allows editing the processed list of crops, their varieties and hybrids, their characteristics, indicators for selection, etc. The administrative module allows importing data from Microsoft Excel and Word, and performs automated data transfer to the Web-server for correct operation and updating of the Online and Android applications.

The sequence of the choice of varieties and hybrids of agricultural crops is represented by an understandable user interface and consists of only two stages:

- $\quad$ in the operating mode, the authorized user chooses the crop of interest;

- for the selected crop indicates the planned cultivation region and the required target values.

Based on the indicated values of the indicators and the chosen region of the Russian Federation, the user receives a list of recommended varieties (hybrids) that correspond, or within the permissible limits (specified by the system administrator), partially correspond to the entered request with the possibility of the further studying their detailed description.

The conducted analysis of the experimental data obtained during many years of field experiments at the Kursk Federal Agrarian Scientific Center and generalization of the research results of scientific research and educational organizations as well as practices of other agricultural enterprises in the European part of the Russian Federation, revealed the optimal conditions for the use of adaptive technologies for the main cultivation crops of various intensity levels, on the basis of which a regulatory reference database, a mathematical model, and an algorithm for choosing adaptive technologies for cultivating leading crops were developed. The algorithm for choosing adaptive agricultural technology is based on sequential overcoming the key soil, climate and agricultural factors that limit obtaining the most profitable crop yields with high quality indicators while observing the principles of resource saving.

When adapting agrotechnology to the prevailing natural environment and features of the landscape, it is necessary to differentiate each agrotechnological technique by the appropriateness of its application to current conditions, taking into account knowledge of the history of maintaining the fields and their current state. From this perspective, the scientifically based choice of the most rational fertilizer system for cultivated crops in our algorithm is a multi-stage process of selecting organic and mineral fertilizers as well as land ameliorants based on the analysis of current soil, climatic and agrotechnological conditions (content of nutrients available for plants in soil, soil reaction, grain size distribution of soil, climatic conditions, biological characteristics of agricultural crops, the subsequent impact of fertilizers, field topog- raphy, etc.) using the calculation method of elemental balance [17] based on the soil nutrient-supplying capacity and depletion of nutrients by crops. The selection of the most optimal technique for primary tillage [18] is also based on the analysis of edaphoclimatic and agrotechnological conditions (taking into account grain size distribution of soil, soil density values, tillage techniques for the previous culture, the probability of erosion processes, weediness of fields, etc.). Thus, based on the developed algorithm, key agrotechnological techniques are formed i.e. applying fertilizers and ameliorants as well as the primary tillage; further agricultural techniques such as seed dressing, sowing, plant protection measures and harvesting are subsequently applied.

The work which had been carried out to develop an algorithm for the rational choice of highly profitable adaptive technology for cultivating grain crops allowed us to proceed to the final stage of the study i.e. creating the Program for the Rational Choice of Adaptive Technology for Grain Crops Cultivation for Various Conditions of the European Part of the Russian Federation application; being scientifically based, applying computer analysis of the available data, this application allows agricultural producers to use promptly edaphoclimatic and agrotechnological resources of agricultural territories in order to increase the profitability of the applied agricultural technologies as well as to ensure the environmental orientation of the technologies used by the efficient application of mineral fertilizers, fuel and chemical plant protection products, the choice of the optimal variety or hybrid of grain crops, used agricultural machinery taking into account import substitution requirements and economic efficiency.

The sequence of choosing highly profitable adaptive technology for cultivating leading crops is presented in Table 1 and is a combination of the user's operating mode (in which the user enters data describing edaphoclimatic and agrotechnological conditions of the working area) and the decision support mode (in which the data entered by the user are analyzed taking into account the existing standards, and then the calculation of doses and timing of fertilizers, ameliorants and plant protection products is carried out).

The prototype software package is currently available at https://agro.workspark.ru/. Program created with Node. js, React, MongoDB (figure 3) and Express.

Currently, the developed software has been tested in a number of farms in the Kursk region, and positive reports have been received.

The issue of the software complex commercialization is being considered both by providing paid access to the full functionality of the program and by placing advertising materials in the system of organizations involved in the production and sale of original seeds and agricultural products, including fertilizers, and (or) machinery, as well as by obtaining a small percentage of the sales of agricultural products using the platform. 
Table 1: The main stages of the rational choice of highly profitable adaptive technology for grain crops cultivation

\begin{tabular}{|l|l|}
\hline \multicolumn{1}{|c|}{ User operation mode } & \multicolumn{1}{|c|}{ Decision support mode } \\
\hline $\begin{array}{l}\text { The choice of the crop planned for cultivation with } \\
\text { an indication of the cultivation region }\end{array}$ & $\begin{array}{l}\text { Determining possibilities of cultivating the chosen crop in the } \\
\text { chosen region: if the chosen crop is suitable for cultivation in } \\
\text { the chosen region, then the choice of technology goes further; } \\
\text { if it is not suitable, then the user is proposed to either adjust the } \\
\text { choice of a crop or the choice of a region }\end{array}$ \\
\hline $\begin{array}{l}\text { Specification of the crop preceding to the chosen } \\
\text { one }\end{array}$ & $\begin{array}{l}\text { Determining the feasibility of cultivating a crop according to } \\
\text { a given preceding one: if it is feasible to cultivate a chosen } \\
\text { crop according to a specified preceding one, then the choice } \\
\text { of technology goes further, if it is not feasible, the user is pro- } \\
\text { posed to adjust the choice of a crop }\end{array}$ \\
\hline $\begin{array}{l}\text { Filling the characteristics of the arable soil layer of } \\
\text { the working area (soil type, grain size distribution, } \\
\text { humus content in the soil, \%; depth of the arable } \\
\text { layer, cm; soil density, g/cm3; soil acidity, erosion } \\
\text { processes) }\end{array}$ & $\begin{array}{l}\text { Determining the feasibility of applying fertilizers (organic and } \\
\text { macro-fertilizers) as well as ameliorants; recommendations on } \\
\text { the necessary doses and timing of application (using the cal- } \\
\text { culation method of elemental balance), the most rational tech- } \\
\text { nique of basic tillage and seed application rates }\end{array}$ \\
\hline $\begin{array}{l}\text { Filling the phytosanitary characteristics of the work- } \\
\text { ing area (technique of soil tilling for the preceding } \\
\text { crop, weeds, diseases and pests, numerically ex- } \\
\text { ceeding the economic threshold of harmfulness) }\end{array}$ & $\begin{array}{l}\text { Determining the appropriateness of the use of plant protection } \\
\text { products, recommendations on the necessary doses and tim- } \\
\text { ing of application }\end{array}$ \\
\hline $\begin{array}{l}\text { Filling the climatic characteristics of the work area } \\
\text { in the period prior to harvesting }\end{array}$ & $\begin{array}{l}\text { Determining the most appropriate technique of harvesting a } \\
\text { cultivated crop (including the possibility of desiccation of crops) }\end{array}$ \\
\hline
\end{tabular}

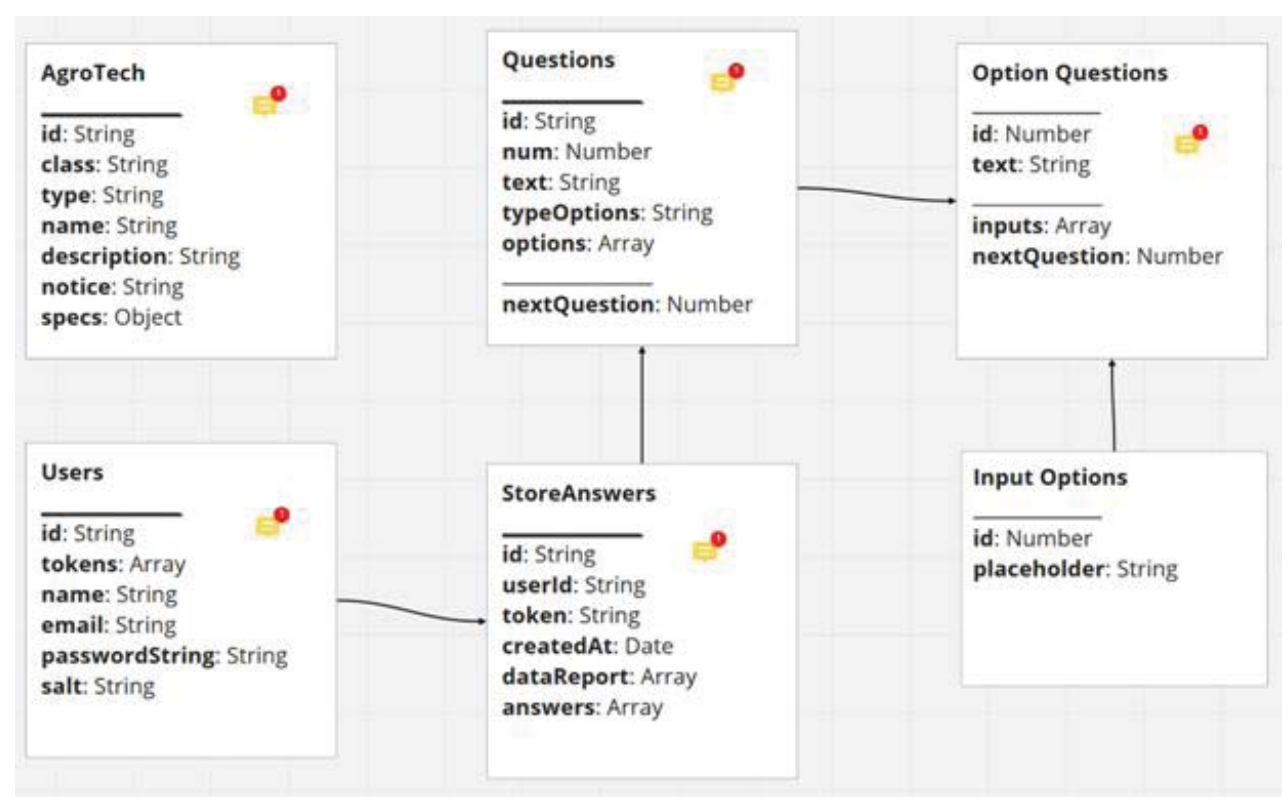

Figure 3: The fragment of system database created with Mongo DB

The following stages of the development of the software package are as follows:

1. Improving the functionality of the user's personal account;

2. Implementation of the system of the direct order for agricultural products;

3. ranslation of the application into other languages (both CIS countries and other states), filling the database with the corresponding crops and varieties (hybrids) cultivated in foreign countries.

\section{CONCLUSIONS}

The Program for the Rational Choice of Highly Cost-Effective Adaptive Technology of Grain Cultivation for Various Conditions of the European Part of the Russian Federation promptly allows specialists of agricultural enterprises and farms, experts, students of agricultural universities and colleges to get acquainted with the list of varieties / hybrids of the leading ear, cereal and leguminous crops (at the current stage this database includes more than 600 items), approved for cultivation on the ter- 
ritory of the European part of the Russian Federation, to make scientifically based choice of varieties / hybrids of grain crops according to specified parameters as well as to form adaptive technology (or separate leading agricultural practices) for their cultivation based on the analysis of compliance of the existing soil, climatic and agrotechnical conditions of agricultural territories with the regulatory reference data by means of dialogue-based queries in an automated form both remotely and online. Using a database of agricultural machines, tools and units of domestic and foreign production (more than 240 items) will help to form a technological map as well as to evaluate the effectiveness of this event both economically and energetically. The program provides for the adjustment of the regulatory database not only in relation to the conditions of the European part of Russia but also for other regions of the Russian Federation as well as for other countries without significant changes to the program code.

The research was carried out within the Grant of the President of the Russia No MK-1064.2018.11.

\section{REFERENCES}

1. (2018) The digitalization of agriculture, http://polit.ru/ article/2018/02/21/sk_digital_farming/

2. (2019) Digital transformation of Russian agriculture, Rosinformagrotech

3. Scherbina, T. A. (2019) Digital transformation of Russian agriculture: experience and prospects, Russia: development trends and prospects, vol. 14, pp 450-453

4. (2018) Digitalization of agricultural production in Russia for the period 2018-2025, Research of the cooperative project "German-Russian agrarian and political dialogue"

5. Krupina, G. D., Safiullin, N. A., Kudryavtseva, S. S., Savushkina L. N., and Kurakova, C. M. (2020) Analysis of the digitalization efficiency in agricultural complex in the Republic of Tatarstan, BIO Web of Conferences, 17, 00230, https://doi.org/10.1051/bioconf/20201700230FIES 2019. (6\%)

6. (2016) Strategy of scientific and technological development of the Russian Federation

7. Gostev, A. V., Pykhtin, A. I., \& Popadinets, R. V. (2019) Selection of Adaptive Agricultural Technologies in Digital Agriculture, KnE Life Sciences, vol. 4(14), pp 51-61. https://doi.org/10.18502/kls.v4i14.5580
8. Yakushev, V. V., Yakushev, V. P. (2018) Prospects for "smart agriculture" in Russia,Bulletin of the Russian Academy of Sciences, vol. 88, No 9, pp 773-784

9. Stepnih, N. V., Zargaryan, A. M., Zhukovam O. A. (2017) A computer program for the design of technologies of cultivation of agricultural crops, Agrarian Bulletin of the Urals, vol. 3, pp 54-58

10. Isakova, S. P., Lapchenko, E. A. (2016) Web-based complex based on a mathematical model of optimal machine and tractor fleet formation, Siberian Bulletin of agricultural science, vol. 5 (252), pp 76-82

11. Anderson, R., Keshwani, D., Guru, A. etc. (2018) An integrated modeling framework for crop and biofuel systems using the DSSAT and GREET models, Enviromental modeling and Software, vol.108, pp 40-50

12. Dzotsi, K. A., Basso, B., Jones, J. W. (2013) Development, uncertainty and sensitivity analysis of the simple SALUS crop model in DSSAT, Ecological Modelling, vol. 260, pp 62-76

13. Lopez-Requelme, J., Pavon-Pulido, N., Navarro-Hellin, H. A. (2017) Software architecture based on FIWARE cloud for precision agriculture, Agricultural water management, vol. 183, pp 123-135

14. (2018) Results of the all-Russian agricultural census of 2016, Federal state statistics service, vol. 1

15. (2019) State register of selection achievements approved for use. Vol. 1. "Plant Varieties" (official publication), Rosinformagrotech

16. Pykhtin, A. I., Gostev, A. V., Alimli, D. A. (2018) Model, algorithm and software for automated selection of varieties and hybrids of cereals, Proceedings of Southwest State University. Series: Management, computer engineering, computer science. Medical instrumentation, vol. 3 (28), pp 25-34.

17. Pykhtin, I. G., Gostev, A. V., Pykhtin, A. I. (2017) Software decision support in the cultivation of crops, Journal of Engineering and Applied Sciences, vol. 12(20), pp 5338-5342

18. Gostev, A.V., \& Pykhtin, I. A. [2017] Structure of costs and expenditures in agro technologies of different intensity levels. Journal of Applied Engineering Science, 15(4), 463-466.

Paper submitted: 27.04.2020.

Paper accepted: 06.05.2020.

This is an open access article distributed under the CC $B Y-N C-N D 4.0$ terms and conditions. 